\title{
Future control architecture and emerging observability needs
}

\author{
Morch, Andrei Z. ; Jakobsen, Sigurd Hofsmo; Visscher, Klaas; Marinelli, Mattia
}

Published in:

Proceedings of International Conference on Power Engineering, Energy and Electrical Drives 2015

Link to article, DOI:

10.1109/PowerEng.2015.7266325

Publication date:

2015

Document Version

Peer reviewed version

Link back to DTU Orbit

Citation $(A P A)$ :

Morch, A. Z., Jakobsen, S. H., Visscher, K., \& Marinelli, M. (2015). Future control architecture and emerging observability needs. In Proceedings of International Conference on Power Engineering, Energy and Electrical Drives 2015 (pp. 234-238). IEEE. https://doi.org/10.1109/PowerEng.2015.7266325

\section{General rights}

Copyright and moral rights for the publications made accessible in the public portal are retained by the authors and/or other copyright owners and it is a condition of accessing publications that users recognise and abide by the legal requirements associated with these rights.

- Users may download and print one copy of any publication from the public portal for the purpose of private study or research.

- You may not further distribute the material or use it for any profit-making activity or commercial gain

- You may freely distribute the URL identifying the publication in the public portal 


\section{Future control architecture and emerging observability needs}

\author{
Andrei Z. Morch and \\ Sigurd Hofsmo Jakobsen \\ Department of Energy Systems \\ SINTEF Energy Research \\ Trondheim, Norway
}

\author{
Klaas Visscher \\ Technical Sciences \\ TNO \\ Groningen, The Netherlands
}

\author{
Mattia Marinelli \\ Department of Electrical Engineering \\ DTU, Risø Campus \\ Roskilde, Denmark
}

The paper presents the first findings from workpackage "Increased Observability" in EU FP7 project ELECTRA. Accommodation of intermittent generation into the network and its reliable operation require a gradual evolution of the network structure and in particular improvement of its monitoring or observing. The present practices of observing distribution networks are quite limited and vary from country to country. New network architectures are expected to evolve in the close future, including web-of-cells (concept defined in ELECTRA), which will result in new control schemes, significantly different from the existing. Several new observability needs have to be met in order to secure operation of the future networks.

Keywords-control architectures;

accommodation

of renewables, ancillary services, observable

\section{INTRODUCTION}

The European Union has defined several ambitious climate and energy targets including 20-20-20:

- A $20 \%$ reduction in EU greenhouse gas emissions from 1990 levels

- Raising the share of EU energy consumption produced from renewable resources to $20 \%$

- A 20\% improvement in the EU's energy efficiency

and the 2050 decarbonisation roadmap [3]. Achieving these goals will require a major transfer from conventional generation to Renewable Energy Sources (RES) on different scales, from offshore wind farms to small-scale photovoltaics (PVs), feeding into networks on various voltage levels. Following the same goal, electrification of transport (EVs) and increased use of heat pumps for space heating will contribute to changes on the consumption side, making it more volatile and difficult to predict due to temperature dependency. Changes on the consumption side will however provide possibility to utilise Demand Response Resources (DRR).

Great challenges are anticipated for the secure operation of the future power system, in connection with the foreseen transition from centralised to decentralised generation. Implementation of novel control strategies will enhance flexibility of the power system enabling it to accommodate a broad spectrum of decentralised and intermittent (renewable) energy sources in order to provide sustainable and economical supply of electricity. Accommodation of intermittent generation into the network and its reliable operation requires a gradual evolution of the network structure and in particular improvement of its monitoring or observing.

This paper is based on European FP7 project ELECTRA (2013-2017) [1]. The overall objective of the ELECTRA project in brief is to develop radically new control solutions towards 2035 and beyond. Workpackage "Increased observability" plans to develop and implement adequate concepts and methods for sufficiently observing the state of the future power system for the three identified axes:

- Pan-European

- Vertically-integrated

- $\quad$ Local (Horizontal/ Distributed)

The suggested observability schemes will be implemented in a generic lab platform programmable in an advanced language.

This paper presents the first findings from workpackage "Increased Observability" of ELECTRA. The interested readers are advised to read the corresponding technical report from ELECTRA [4].

\section{THE PRESENT OBSERVABILITY PRACTICES AND THE LIMITATIONS}

\section{A. Definition of an observable}

In the scope of the present paper an observable is a uniquely valued function of a number of measurable quantities in a physical system model. An observable can either be a scalar or vector ("State Vector") that relates to measured (observed) values in the present or past. An observable is calculated from measurements in the system.

\section{Example:}

The RMS value of an AC voltage is an observable, and so is the complex representation of an $\mathrm{AC}$ voltage. Both are computed or derived from an actual measured voltage as a function of time. The RMS voltage is a scalar, and the complex voltage is a vector. 
Table II-1 Observables in use today in distribution networks (based on a survey conducted in ELECTRA project).

\begin{tabular}{|l|l|}
\hline \multicolumn{1}{|c|}{ Observable } & \multicolumn{1}{c|}{ Comment } \\
\hline Current MV-level & $\begin{array}{l}\text { Most respondents responded that current is measured at the MV level, both at HV/MV transformers and MV/LV transformers. } \\
\text { Some countries also measure the current at connection points for industrial customers. It varies from country to country whether } \\
\text { or not is a three phase measurement or if the power factor is measured. }\end{array}$ \\
\hline $\begin{array}{l}\text { Voltage MV-level } \\
\text { three phases are measured. Some also report that voltage is measured at points of special interest. }\end{array}$ \\
\hline Active power MV-level & $\begin{array}{l}\text { This is mainly measured at HV/MV transformers. When it is measured at MV/LV transformers it is mainly used for billing } \\
\text { purposes. It is also measured for distributed generation resources. In addition to using power measurements for billing purposes } \\
\text { they are also used as input for load and generation forecasts. }\end{array}$ \\
\hline Reactive power MV-level & Reactive power is mostly reported to be measured at HV/MV transformers, and at connected distributed generation units. \\
\hline $\begin{array}{l}\text { Reactive power } \\
\text { banks }\end{array}$ & Some countries report that reactive power compensation is measured at LV level and at primary substations \\
\hline Position of switches & Most respondents reported that the position of switches are measured at both LV and MV level \\
\hline State of fuses & One respondent reported that the state of the fuses at LV level is measured \\
\hline Current LV level & $\begin{array}{l}\text { Half of the respondents reported that the current is measured at LV level, some of them reported that these measurements were } \\
\text { available for some busbars and substations }\end{array}$ \\
\hline Voltage LV level & Two respondent reported that voltages are measured for some points at LV level, but that extensive use is planned \\
\hline Frequency & One respondent reported that frequency is measured \\
\hline
\end{tabular}

Forecasts are not considered to be observables, but merely predictions of the future values of observables. Forecasts will differ from observable values to be measured in future and therefor are not observables, as future system states cannot be measured.

Transition time is defined as time to complete the transition from a stationary system state to the next stationary one, after a switching event occurs

\section{B. Survey of the observability practices}

In order to define a present status and establish a common reference to observing practices, a limited survey of the existing observability practices was conducted. The survey covered eight European countries and differentiated the results according to Transmission and Distribution System Operators (TSO/DSO) operations (see Table II-1).

Several important conclusions have been made after this survey. Practices for Observing of the Transmission Networks (TNs) appear to be quite similar (most likely due to compliance with ENTSO-E's requirements) with very little variation among countries. The situation is quite different, when it comes to the Distribution Networks (DNs).

- Observing of the Distribution Network varies from country to country and is in general limited i.e. "observability decreases as the voltage level decreases"

- DSOs seem to be most concerned with what happens at HV/MV connection points and connection of big customers

- Most participating countries have already now intentions for improving observability of the distribution grid

After conducting the survey it became even more obvious that the present practices for observing both Transmission and especially Distribution networks are not adequate for the expected transformation of the power sector in order to meet the European 20/20/20 goals

\section{MEETING THE FUTURE CHALLENGES}

\section{A. Cell-concept as an alternative for the future network architecture}

Based on the future scenarios, ELECTRA project has developed high level functional requirements for two different types of future control systems: centralised and decentralised architecture [2]. While the first proposes a gradual evolution of the traditional centralised controls, the second architecture is based on a novel and rather radical concept, which was coined web-of-cells by ELECTRA.

Following this, the future European power grid will be decomposed into a new structure - "web-of-cells", where the cells are defined as a group of interconnected loads, distributed energy resources and storage units within well-defined electrical boundaries corresponding to a physical portion of the grid and corresponding to a delimited geographical area (see Figure II-2).

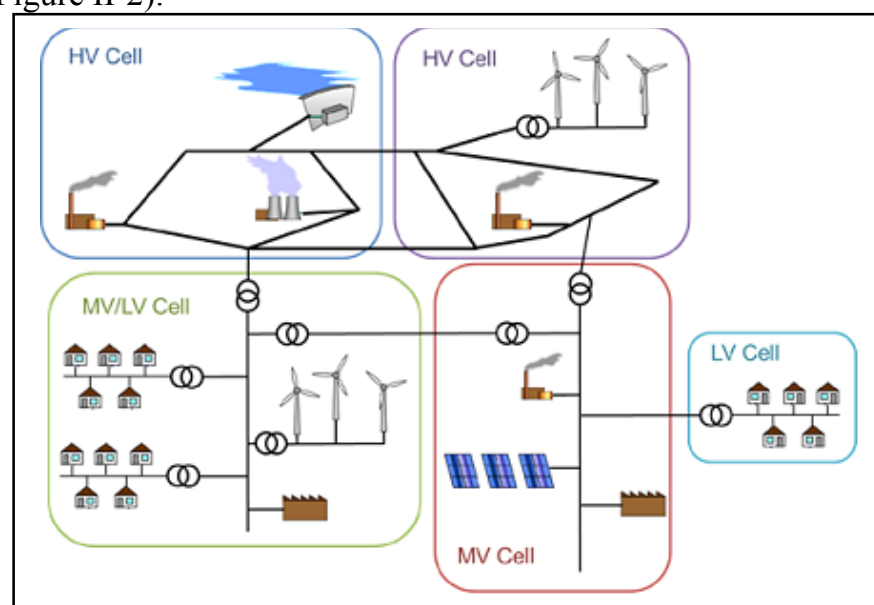

Figure II-2 Example of cell-based architecture. Source: (2)

Figure II-1 Example of cell-based architecture. Source: (2) 
Table III-1 Summary of the control schemes identified for two type of architectures

\begin{tabular}{|c|c|}
\hline Centralised architecture & Decentralised web-of-cell architecture \\
\hline \multicolumn{2}{|c|}{ Frequency control } \\
\hline $\begin{array}{l}\text { Primary frequency control uses new resources as frequency-controlled demand } \\
\text { from distributed loads and distributed control/MicroGrids }\end{array}$ & $\begin{array}{l}\text { Inertia frequency control (IFC), where each unit, involved in inertia } \\
\text { control, automatically changes its active power contribution or consumption } \\
\text { depending on certain predefined characteristics. }\end{array}$ \\
\hline $\begin{array}{l}\text { Secondary frequency control includes an increased involvement of Non- } \\
\text { programmable RES with centralized and local dispatching. The latter entails DSO } \\
\text { to be responsible for the services towards TSO, participating in the ancillary } \\
\text { service market. }\end{array}$ & $\begin{array}{l}\text { Frequency containment control (FCC) will not be fundamentally } \\
\text { changed compared to today's schemes, except that the resources providing } \\
\text { containment reserves will be different: generating units (in the broades } \\
\text { sense) as well as loads and storage distributed across the power grid (within } \\
\text { each cell). }\end{array}$ \\
\hline $\begin{array}{l}\text { Tertiary frequency control includes a number of potential resources at both } \\
\text { transmission and distribution levels: consumers at LV distribution level, } \\
\text { Distributed Generators as wind and PV, centralised storage as pumped hydro and } \\
\text { distributed storage as EVs. }\end{array}$ & $\begin{array}{l}\text { Balance restoration control (BRC) initiates the restoration of the cell } \\
\text { balance and load flows based on local information. It is assumed that } \\
\text { (almost) all prosumers, that are connected through public communication } \\
\text { infrastructure, will be able to offer fast FRR capacity, e.g. through their } \\
\text { flexible loads, and possibly local storage. } \\
\text { Balance steering control (BSC) will relieve the FRR and have pro-active } \\
\text { activation based on prognoses. This control deploys resources not only }\end{array}$ \\
\hline
\end{tabular}
Voltage control within the cell but also from neighbouring cells.

Primary voltage control is a process that is performed locally by each network element which has voltage control capability. The future schemes in addition to the conventional power plants are expected to include RES and Microgrids.

The secondary voltage control in future grids can cover both the regional control within a certain zone of the TSO's control area and the voltage control at the distribution system level. The secondary voltage and reactive power control at the transmission grid controls the reactive power at certain pilot-nodes in the transmission grid. Each pilot-node is representative for the voltage within a certain zone. The secondary controller changes the reactive power provided by the devices (power plants or reactive power equipment of the TSO (e.g. capacitors banks) or reactive Power provided by distribution grids) within this zone until the voltage at the pilot-node is at the desired level.

Tertiary voltage control is a process that acts on a system wide scale and in a time range of about 10 to 30 minutes. The objective of tertiary voltage is to optimize the operation of the network by maintaining the required voltage quality and the substitution of reactive reserves.

\section{B. Mapping of control types with the new architecture concepts}

These two control architectures are foreseen to comprise two sets of control types, which are presented in Table III-1. The main challenge with regard to observability was to point out the new observability needs, which are likely to emerge in these two alternative future network architectures. These needs will be more specifically addressed in the succeeding tasks in ELECTRA project.

\section{EMERGING OBSERVABILITY NEEDS IN THE NOVEL CONTROL SCHEMES}

The above mentioned controls schemes were further elaborated in ELECTRA and defined as a set of specific Use Cases for the future scenarios for ancillary services (2030 and beyond), build on standard Intelligrid IEC/PAS 62559 specification for development of use cases [5].

The scope of this paper does not allow presenting these use cases in details, but interested readers are advised to read [2].
Primary voltage control is not expected to have fundamental changes compared to today's primary voltage control, except that the resources used will be different: generating units (in the broadest sense) as well as loads, storage devices and FACTS. These resources will be procured within every cell, and will thus be distributed over different voltage levels.

Post-primary voltage control (PPVC) has the commitment to bring the voltage levels in the nodes of the power system back to nominal values while optimizing the reactive (and active) power flows in order to reduce the losses in the network.

Each cell is responsible for its own voltage control while a close coordination between neighbouring cells guarantees the provision of PPVC service between neighbouring cells.
The present study made a deep qualitative evaluation of these use cases aligning observability needs with technical challenges in the new control schemes and defined set of physical requirements applicable for each observability need.

\section{A. Physical requirements for the observables}

Physical requirements for the observables define more specifically quantifiable physical attributes, which are necessary in order to meet the observability needs. The following physical requirements have been identified:

Required time resolution (sampling frequency): number of samples obtained in one second. This requirement can be described as a min value.

Maximum latency allowed: for data or data transfer from source to destination. This requirement can be described as max possible period of time. Several observability needs have to be met within a certain time period and may become worthless if not. 
Table IV-1 Observability needs and requirements for the future tertiary frequency regulation schemes for Aggregators

\begin{tabular}{|c|c|c|c|}
\hline Observability needs & Challenges & Observable & Requirement \\
\hline 1. Prosumers' real time load and flexibility & $\begin{array}{l}\text { To participate in the market the } \\
\text { aggregators will have to know the } \\
\text { flexibility of the loads, as well as how } \\
\text { much load there is at any given moment }\end{array}$ & $\begin{array}{l}\text { Prosumers' load and } \\
\text { prosumers' flexibility }\end{array}$ & $\begin{array}{l}\text { Physical location, sampling } \\
\text { frequency, and latency, time stamp }\end{array}$ \\
\hline 2. Geographical distribution of the reserves & $\begin{array}{l}\text { The aggregators may not be operating } \\
\text { the networks, but they will have to } \\
\text { provide the geographical distribution of } \\
\text { the reserves to the operator. }\end{array}$ & Same observable as above & \\
\hline $\begin{array}{l}\text { 3. Data collection as input for the forecasting } \\
\text { algorithms. }\end{array}$ & $\begin{array}{l}\text { The forecasting algorithms will have to } \\
\text { couple weather and loading data. This } \\
\text { increases the need for correctly time } \\
\text { stamped data. }\end{array}$ & $\begin{array}{l}\text { Meteorological data used as } \\
\text { input to operators and } \\
\text { forecasts(not an observable } \\
\text { by our definition) }\end{array}$ & $\begin{array}{l}\text { Physical location, } \\
\text { frequency, time stamp }\end{array}$ \\
\hline
\end{tabular}

Reference location according to the network's voltage level (HV; MV; LV or more specific). The reference location, where the observability has to be met. It does not necessarily mean that the actual measurements have to be done in the same place

The observability can be derived based on measurements in other places or/and calculations. This applies to local observables and may be irrelevant in case of global observables as for example frequency

Reference location to the network's topology (specific network components). It does not necessarily mean that the actual measurements have to be done in the same place. The observability can be derived based on measurements in other places or/and calculations. This applies to local observables and may be irrelevant in case of global observables as for example frequency.

Time stamp: For many observables it is important to know with ample detail when they were observed.

Accuracy: the closeness of computations or estimates to the exact or true values. Inaccuracies of measuring the "true" variable values due to the fallibility of the measuring instrument, data entry errors or respondents' error are defined by measurement error value.

Reliability: extent to which a variable or a set of variables is consistent in what it is intended to measure. If multiple measurements are taken, the reliable measures will all be very consistent with in their values

\section{B. Observability needs for the future ancillary services}

The identified observability needs have been derived for each type of ancillary services (control levels) and market role TSO; DSO and Aggregator. The following Table IV-I presents an overview of the identified observability needs for Aggregators involved in tertiary frequency regulation as an example. Similar tables have been created for other roles and control schemes.

Despite significant differences between centralised and decentralised architectures, the identified observables appear to be very similar. The reason for this is most likely the fact that they are both dependent on the same future scenario. This means that there are two answers to the same set of challenges.

Furthermore, the mapping of observability needs and requirements has identified a comprehensive list of the emerging observability needs. It is however necessary to mention specifically that the most relevant needs are state estimation and the availability of reserves.

\section{CONClusions}

After conducting the survey it became even more obvious that the present practices for observing both transmission and especially distribution networks are not adequate for the expected transformation of the power sector in order to meet the European 20/20/20 goals.

Therefore the study has identified the potential areas where observables should be developed in order to meet challenges of the future controls schemes. The most sought after observable being prosumer flexibility. This observable also touches upon several other aspects making the observability needs' study relevant for both the centralised and decentralised futures. The biggest changes with respect to the observability needs are expected to be due to the introduction of more RES, new actors and devices.

The most interesting observables to further investigate are the following:

- The observables directly related to the web-of-cells concept

- The observables related to inertia control

- Prosumers' flexibility

- Available control reserves

- State estimation

The two last items on the list are directly related to the introduction of more RES, growing share of prosumers and new devices. 
The important questions being identified:

- How can the operator observe the amount of available reserves provided by RES and prosumers?

- How does new devices affect the state of the system.

It is outside the scope of this study to develop these observables. However, these are the areas where subsequent tasks in ELECTRA project should put their focus to ensure that the ELECTRA visions are accomplished.

\section{REFERENCES}

[1] http://www.electrairp.eu (ELECTRA IRP official web site)

[2] C. Caerts et al. ELECTRA Technical Report D3.1 "Specification of Smart Grids high level functional architecture for frequency and voltage control" December 2014
[3] EU Energy Roadmap 2050 http://ec.europa.eu/energy/energy2020/roadmap/doc/com_2011_8852_e n.pdf

[4] A. Z. Morch et al. ELECTRA Technical Report D5.1 "Adaptive Assessment of Future Scenarios and Mapping of Observability Needs" December 2014

[5] IEC/PAS 62559 ed1.0. Available from: http://webstore.iec.ch/Webstore/webstore.nsf/ArtNum_PK/38920?Open Document

[6] The EU 2020 climate and energy package

[7] ENTSO-E Network Code on Load-Frequency Control and Reserves (NC-LFCR) 2013-06-28

[8] Andersson G. "Dynamics and Control of Electric Power Systems", EEH - Power Systems Laboratory, ETH Zurich, February 2012

[9] Flexibility: The role of DSOs in tomorrow's electricity market. EDSO for Smart Grids. June 2014.

[10] Webinar "Observables Inventory Survey" (video) https://docs.google.com/file/d/0B5F9i09SSxQ5VkZtcW5Nc0E5Ykk/edi $\underline{\mathrm{t} \text { pli }=1}$ 